\title{
Înregistrarea cronologiei intensității fructificației pentru prin- cipalele specii forestiere din România
}

\section{Palaghianu}

\section{Introducere}

Atât literatura de specialitate cât și practica forestieră oferă informații legate de fructificația abundentă a speciilor forestiere. În limba
Palaghianu C., 2019. Constructing the masting chronology for the main forest tree species in Romania. Bucov. For. 19(2): 183-188.

Abstract. Masting represents a reproductive strategy in plant species, characterized by the synchronous population behaviour of producing large crops of flowers, fruit or seeds with a more or less regular frequency. This synchronous and highly variable production of large crops has practical importance for foresters. The information related to the variability of seed production should be used for scheduling silvicultural treatments, taking into account that regeneration cuttings must be synchronized with the mast years. Consequently, foresters should collect these masting records and use it the decision-making mechanisms of forest management.

Records of masting were used in the past, on regular basis, but in the last two decades this information is no longer used or archived in Romania, by forest managers. Therefore, the main objective of the CRONOFOR initiative is the construction of masting chronologies for the main forest tree species in Romania (Norway spruce, silver fir, beech, oak and sessile oak).

The masting data will be retrieved mainly from forest management units and then it will be processed, verified and uploaded to a database that will be available online to be used by both forest practitioners and researchers. Each record contains the basic information on the masting event: species, year of observation, fruiting intensity (an ordinal index of masting with 5 classes) and geographical location data of the observations.

The project aims to arouse the interest of foresters and researcher for masting events, by creating a functional technical platform available online, which can be further developed by other means (e.g. citizen-science, GIS integration). Information from masting chronologies could also become useful in studies that would determine, for example, how the tree species reproductive patterns will adapt to climate change.

Keywords: masting records, seed production, fructification.

Author. Ciprian Palaghianu (cpalaghianu@usv.ro) - Ștefan cel Mare University of Suceava, Forestry Faculty, 13 Universitătii, 720229 Suceava, Romania.

Manuscript received December 14, 2019; revised December 24, 2019; accepted December 29, 2019; online first December 31, 2019. 
sit un alt termen pentru a desemna anii situați între evenimentele cu fructificație abundentă: ani cu stropeli. Acest lucru arată perceperea variabilității producției de fructe sau semințe și înțelegerea mecanismelor fructificației arborilor forestieri.

Informațiile legate de variabilitatea producției de semințe sunt (sau ar trebui să fie) folosite în practica silvică, tiinând cont de faptul că, atunci când se apelează la soluția regenerării naturale, tăierile de însămânțare trebuie sincronizate cu anii de fructificație abundentă ai speciilor forestiere. În consecință, managementul silvic trebuie să înregistreze și să folosească în mecanismele decizionale informațiile legate de variabilitatea fructificației. În literatura de specialitate de la noi sunt date metode de prognoză și evaluare a fructificației, iar practica silvică le utiliza, înregistrând cronologia fructificațiilor abundente.

Schimbările politice și sociale apărute după anul 1990, reflectate şi în context forestier (Palaghianu și Nichiforel, 2016), precum și modul în care managementul regenerărilor a fost ajustat în ultimele decenii (Palaghianu şi Dutca, 2017) au condus la situaţia actuală în care înregistrarea informațiilor legate de fructificația arboretelor nu mai reprezintă o preocupare a practicii silvice. Chiar dacă, în mod izolat, observații privitoare la variabilitatea producției de fructe și semințe se mai fac, aceste informații nu mai sunt înregistrate, centralizate sau arhivate. În condițiile actuale, în care modalitatea de păstrare și gestionare a informațiilor în format electronic este mult mai ușoară ca în trecut, iar accesul unui număr mare de utilizatori la baze de date este facilitat de dezvoltarea infrastructurii rețelelor de date, este nevoie de o reevaluare a modului în care informațiile legate de variabilitatea fructificațiilor anuale sunt păstrate și utilizate. Acest lucru este necesar, cu atât mai mult cu cât interesul pentru dezvoltarea unor cronologii ale acestor evenimente deosebite din ecosistemele forestiere este puternic susținut și de comunitatea științifică (Drobyshev et al., 2014; Ascoli et al, 2017).

\section{Mecanismele declanșării fructificațiilor abun- dente}

Ce reprezintă, totuși, un eveniment de fructificație abundentă? Este un proces ecologic important în comunitățile vegetale, care arată un tipar reproductiv specific, proces caracterizat prin producerea de către indivizii unei populații a unei cantități remarcabile de fructe, conuri sau seminte cu o anumită periodicitate, mai mult sau mai puțin regulată (Kelly, 1994; Herrera et al., 1998). Episoadele de fructificație abundentă nu sunt specifice doar comunităților de arbori, ci multor altor categorii de plante (Kelly și Sork, 2002), dar efectul acestor evenimente în cadrul ecosistemelor forestiere este unul cu implicații multiple asupra numeroaselor specii găzduite de pădure. Probabil datorită acestor efecte în cascadă pe care producția abundentă de fructe o are asupra comunităților forestiere există un interes particular pentru acest subiect din partea specialiștilor în ecologie. Fructificațiile abundente modifică substanțial densitatea populațiilor de animale, păsări și insecte (Vander Wall, 2002; Zwolak et al., 2016), dinamica regenerării arboretelor (Koenig și Knops, 2005), fluxurile de nutrienți și serviciile ecosistemice (Miyazaki, 2013) și pot influența chiar starea de sănătate a comunităților umane (Tersago et al., 2009).

În prezent, majoritatea specialiștilor consideră că acest tipar reproductiv specific poate fi caracterizat prin trei parametri: variabilitate, sincronizare și frecvență (Vacchiano et al., 2018). Variabilitatea este definită de diferențele înregistrate între producțiile anuale de fructe, conuri sau semințe. Gradul de sincronizare arată modul în care indivizii sau populațiile de arbori din aceeași specie sau chiar din specii diferite își sincronizează, uneori pe suprafețe destul de întinse, efortul reproductiv. Ultimul parametru, frecvența, arată periodicitatea cu care evenimentele de o anumită intensitate se repetă în decursul intervalelor de timp.

Chiar dacă evenimentele și efectele fructificațiilor abundente au fost amplu studiate, în situații diverse, mecanismele prin care se 
declanșează aceste episoade nu sunt pe deplin elucidate. Fenomenul a fost explicat prin ipoteze care țin cont de condițiile de mediu sau de resursele disponibile, dar sunt și studii care oferă explicații mecaniciste/fiziologice sau evolutive/ecologice.

Un aspect interesant legat de apariția episoadelor cu fructificaţie abundentă se referă la sincronizarea efortului reproductiv al indivizilor. Dacă variabilitatea producției și frecvența pot fi explicate prin mecanisme individuale, gradul de sincronizare între indivizi și populații arată mai degrabă o strategie de regenerare sau adaptare evolutivă a arborilor. În mod evident sincronizarea întâmplătoare a fructificațiilor nu poate fi explicată doar prin hazard (Palaghianu și Drăgoi, 2015) ci ar putea fi determinată de similaritatea condițiilor şi resurselor dintr-o anumită arie, această ipoteză (resource matching hypothesis) fiind una dintre primele care au încercat să explice acest tipar reproductiv al arborilor (Sork, 1993).

Ulterior această ipoteză a fost atât parțial confirmată cât şi rafinată prin cercetări desfășurate la scară mai largă (Koenig și Knops, 1998), mulți autori considerând că sincronizarea producției de semințe este indusă și de similaritatea condițiilor de mediu dintr-o anumită regiune, prin aşa numitul efect Moran (Ranta et al, 1997; Koenig, 2002). Cercetări mai noi, efectuate în aceeași direcție a studiului influenței factorilor de mediu, au arătat că evenimentele de fructificaţie pot fi influenţate şi de schimbările climatice sau ciclurile solare (Piovesan și Adams, 2005; Pearse et al., 2014).

$\mathrm{O}$ altă teorie foarte apreciată de comunitatea ştiinţifică, lansată acum câteva decenii, teoria sațietății prădătorilor (predator satiation hypothesis) (Janzen, 1971), a oferit un raționament specific ecologiei populațiilor, explicând apariția episoadelor de fructificație abundentă ca o adaptare a populațiilor de arbori la comportamentul consumatorilor de semințe. Cantităţile mari de fructe, conuri și semințe produse cu o anumită periodicitate oferă o șansă mai mare de succes a reproducerii în condițiile în care prădătorii semințelor nu vor putea să consume toată cantitatea de semințe, mult mai mare decât cea produsă în anii ,normali”, cu stropeli.

Există și ipoteze care iau în calcul adaptări evolutive ale speciilor de arbori care implică o creștere a eficienței polenizării în condițiile unui tipar reproductiv bazat pe apariția cu o anumită periodicitate a fructificațiilor abundente (pollination efficiency hypothesis) (Norton și Kelly, 1988) sau modele mecaniciste care explică variabilitatea producției de semințe prin modul de acumulare și ulterior utilizare a resurselor necesare procesului de fructificație (resource budget models) (Isagi et al., 1997).

Toate aceste teorii și ipoteze încearcă să explice mecanismele fenomenului fructificațiilor abundente pentru a putea ulterior să se identifice, modeleze sau prognozeze tipare de fructificație care să poată fi utilizate în procesele decizionale ale managementului forestier sau în alte direcții de cercetare.

\section{Scopul inițiativei GRONOFOR}

În condițiile în care observaţiile privitoare la variabilitatea producției de fructe și semințe ar putea fi folosite atât în practica silvică cât și de comunitatea științifică, apare în mod real necesitatea înregistrării și arhivării acestor date.

Iniţiativa CRONOFOR apare ca răspuns la această necesitate și în urma unor preocupări active în direcția studiului fructificațiilor abundente ale speciilor forestiere, în cadrul acţiunii COST FP1304 PROFOUND (Towards robust projections of European forests under climate change). Obiectivul principal al proiectului CRONOFOR este reprezentat de construirea unor cronologii ale fructificaţiilor abundente pentru principalele specii forestiere din țara noastră. Pentru moment sunt vizate principalele specii (brad, molid, fag, stejar și gorun), dar în măsura în care vor deveni disponibile înregistrări și pentru alte specii forestiere, baza de date va putea fi extinsă, folosind aceeaşi structură și aceeaşi metodologie de culegere și prelucrare a datelor. 
Datele vor fi preluate, prelucrate, verificate şi încărcate într-o bază de date ce va fi disponibilă online, cu acces liber, informațiile putând fi utilizate atât de managementul forestier cât şi de specialiști implicaţi în activităţi de cercetare.

\section{Metodologia de culegere a datelor și manage- mentul bazei de date}

Datele care conțin informațiile privitoare la intensitatea fructificațiilor vor proveni din observațiile efectuate de personalul silvic sau de cercetare în cadrul activităţilor de prognoză sau evaluare a capacității reproductive a arboretelor. Vor fi admise date furnizate prin observațiile personale ale specialiștilor în biologie sau ecologie forestieră, în măsura în care acestea vor fi complete și vor putea fi validate, oferindu-se suport tehnic pentru a asigura integrarea informațiilor în baza de date.

Transmiterea datelor se va face în mod electronic, prin intermediul unui formular online ce va fi accesibil pe pagina web a proiectului (http://www.silvic.usv.ro/cronofor). Înainte de înregistrarea efectivă a informațiilor în baza de date CRONOFOR se va face o validare a valorilor furnizate, pentru a elimina eventuale erori sau inconsistențe.

În cadrul bazei de date, structura a fost creată pentru a permite identificarea unică a evenimentelor de fructificaţie, fiecare înregistrare conținând informații referitoare la:

(i) specie (cod alfanumeric de trei caractere);

(ii) anul producerii evenimentului;

(iii) intensitatea fructificației (apreciată prin clasa de intensitate - valori numerice întregi cuprinse între 1 și 5);

(iv) date de localizare geografică a observațiilor (județ, coordonate GPS din interiorul arboretului în care au fost efectuate observațiile);

(v) comentarii (legate de tipul observațiilor efectuate sau sursa datelor - din documente / arhive forestiere sau date de prognoza obținute prin observații directe în teren).

Pentru a aprecia intensitatea fructificației 186 se folosește o scară de evaluare în 5 trepte. În cadrul acestui sistem de evaluare cu cinci trepte, valoarea 1 reprezintă fructificația cu intensitate foarte slabă (sau lipsa acesteia), 2 - slabă, 3 - medie, 4 - bună și 5 - abundentă. Sistemele de evaluare a fructificației prin cinci clase de intensitate sunt frecvent folosite în sistemele de prognoză din Europa și în lucrările de specialitate care conțin date ale unor cronologii extinse (Hilton și Packham. 2003). În consecință s-a optat pentru acest sistem pentru a asigura compatibilitatea înregistrărilor și interoperabilitatea transferurilor de informații cu bazele de date internaţionale (de exemplu baza de date MASTREE + creată în cadrul rețelei de cercetare MAST-NET). În cazul în care unele observații din arhive mai vechi conțin sisteme de evaluare a fructificației cu trei sau patru trepte, se va folosi un sistem de transformare a acelor valori (Ascoli et al, 2017).

Pentru crearea și managementul bazei de date s-a folosit un sistem open-source de gestiune a bazelor de date relaționale (MySQL), iar formularele online de introducere a datelor, de editare și interogare a bazei de date sunt create cu ajutorului limbajului PHP.

\section{Concluzii}

Inițiativa creării unei cronologii a intensității fructificației pentru principalele specii forestiere din țara noastră este utilă, ținând cont că informațiile oferite de o astfel de bază de date ar putea fi utilizate de specialiștii silvici în planificarea tăierilor de regenerare sau de cercetătorii interesați de variabilitatea anuală a producției de fructe sau semințe.

Proiectul CRONOFOR se dorește a fi un punct de plecare, care să coaguleze interesul pentru studiul acestei strategii reproductive deosebite a plantelor, manifestată prin episoade de fructificație abundentă. Se oferă o platformă tehnică funcțională, care poate să se dezvolte ulterior și prin alte metode.

Din perspectiva posibilităților de dezvoltare ulterioară, vor fi atrase ocoalele silvice interesate în utilizarea acestui instrument in- 
formațional și se vor testa modalități de implementare a unor formulare online care să ușureze culegerea acestor informații. Se va experimenta integrarea unui modul de vizualizare în format GIS, fiecare înregistrare din baza de date având ataşate și informații legate de poziţionarea arboretelor în care au fost efectuate observațiile. O altă posibilitate ce va fi testată în viitor se referă la folosirea unor observații personale, conceptul de "citizen science" fiind unul extrem de popular și dovedindu-se viabil în multe cazuri. În aceeaşi măsură ar putea să se extindă conținutul bazei de date și spre alte tipuri de cronologii forestiere, cum ar fi, de exemplu, cele fenologice, pentru care există preocupări recente intense (Teodosiu și Mateescu, 2004; Keenan, et al. 2014). Coroborarea cu observațiile fenologice ar putea conduce spre creșterea acurateței prognozelor concentrațiilor de polen. În ultimii ani a apărut un interes tot mai mare pentru datele care ar putea fi utile în acțiunile de informare și protejare a cetățenilor de efectele alergenilor. În final, informațiile oferite de o cronologie a intensității fructificațiilor speciilor de arbori pot să fie utile nu doar în practică, pentru sincronizarea tăierilor de regenerare, ci și în cadrul unor studii care să stabilească, de exemplu, modul în care arboretele vor răspunde în viitor, prin efortul reproductiv, la schimbările climatice.

\section{Bihliografie}

Ascoli, D., Maringer, J., Hacket-Pain, A., Conedera, M., Drobyshev, I., Motta, R., Cirolli, M., et al., 2017. Two centuries of masting data for European beech and Norway spruce across the European continent. Ecology, 98 : 1473.

Drobyshev, I., Niklasson, M., Mazerolle, M. J., Bergeron, Y. 2014. Reconstruction of a 253-year long mast record of European beech reveals its association with large scale temperature variability and no long-term trend in mast frequencies. Agricultural and forest meteorology, 192: 9-17.

Herrera, C.M., Jordano, P., Guitián, J., Traveset, A., 1998. Annual variability in seed production by woody plants and the masting concept: reassessment of principles and relationship to pollination and seed dispersal. Am. Nat. 152 (4): 576-594.
Hilton, G. M., Packham, J. R., 2003. Variation in the masting of common beech (Fagus sylvatica L.) in northern Europe over two centuries (1800-2001). Forestry. 76(3): 319-328.

Isagi, Y., Sugimura, K., Sumida, A., Ito, H., 1997. How does masting happen and synchronize? J. Theor. Biol. 187 (2): 231-239.

Janzen, D. H., 1971. Seed predation by animals. Annual review of ecology and systematics, 2: 465-492.

Keenan, T. F., Gray, J., Friedl, M. A., Toomey, M., Bohrer, G., Hollinger, D. Y., ... \& Yang, B. 2014. Net carbon uptake has increased through warming-induced changes in temperate forest phenology. Nature Climate Change, 4(7): 598-604.

Kelly, D., 1994. The evolutionary ecology of mast seeding. Trends Ecol. Evol. 9 (12): 465-470.

Kelly, D., Sork, V. L., 2002. Mast seeding in perennial plants: why, how, where? Annual Review of Ecology and Systematics, 33(1):427-447.

Koenig, W. D., \& Knops, J. M., 1998. Scale of mast-seeding and tree-ring growth. Nature, 396(6708): 225.

Koenig, W. D. 2002. Global patterns of environmental synchrony and the Moran effect. Ecography, 25(3):283288.

Koenig, W., Knops, J. 2005. The Mystery of Masting in Trees Some trees reproduce synchronously over large areas, with widespread ecological effects, but how and why? American Scientist, 93: 340-347.

Miyazaki, Y., 2013. Dynamics of internal carbon resources during masting behavior in

trees. Ecol. Res. 28 (2): 143-150.

Norton, D.A., Kelly, D., 1988. Mast seeding over 33 years by Dacrydium cupressinum Lamb. (rimu) (Podocarpaceae) in New Zealand: the importance of economies of scale. Functional Ecology, 2:399-408.

Palaghianu, C., Dutca, I., 2017. Afforestation and reforestation in Romania: History, current practice and future perspectives. Reforesta, 4: 54-68.

Palaghianu, C., Dragoi, M., 2015. Patterns of mast fruiting - a stochastic approach. Journal of Landscape Management, 6 (2): 56-61

Palaghianu, C., Nichiforel, L., 2016. Intre percepții și precepte în dialogul despre pădurile României (Between perceptions and precepts in the dialogue on Romanian forests), Bucovina Forestiera, 16 (1): 3-8

Pearse, I. S., Koenig, W. D., \& Knops, J. M., 2014. Cues versus proximate drivers: testing the mechanism behind masting behavior. Oikos, 123(2): 179-184.

Piovesan, G., Adams, J. M., 2005. The evolutionary ecology of masting: does the environmental prediction hypothesis also have a role in mesic temperate forests? Ecological Research, 20(6): 739-743.

Ranta, E., Kaitala, V., Lindström, J., \& Helle, E., 1997. The Moran effect and synchrony in population dynamics. Oikos, 78(1): 136-142.

Sork, V. L. 1993. Evolutionary ecology of mast-seeding in temperate and tropical oaks (Quercus spp.). Vegetatio, 107(1):133-147. 
Teodosiu, M., Mateescu, E., 2004. Fenologia-dezvoltare şi perspective. O sinteză. Bucovina Forestieră, 12(1-2): 47-68.

Tersago, K., Verhagen, R., Servais, A., Heyman, P., Ducoffre, G., Leirs, H., 2009. Hantavirus disease (Nephropathia epidemica) in Belgium: effects of tree seed production and climate. Epidemiol. Infect. 137 (2): 250-256.

Vacchiano, G., Ascoli, D., Berzaghi, F., Lucas-Borja, M. E., Caignard, T., Collalti, A., Mairota, P., Palaghianu,
C., Reyer, C., Sanders, T., Schermer, E., Wohlgemuth, T., Hacket-Painn, A., 2018. Reproducing reproduction: How to simulate mast seeding in forest models. Ecological Modelling, 376: 40-53

Vander Wall, S. B., 2002. Masting in animal-dispersed pines facilitates seed dispersal. Ecology, 83(12): 35083516.

Zwolak, R., Bogdziewicz, M., Rychlik, L., 2016. Beech masting modifies the response of rodents to forest management. Forest Ecology and Management, 359: 268-276. 